\title{
Job Control and Coworker Support Improve Employee Job Performance
}

\author{
Makiko NAGAMI'1, 2*, Akizumi TSUTSUMI ${ }^{3}$, Masao TSUCHIYA ${ }^{4}$ and Kanehisa MORIMOTO ${ }^{1}$ \\ ${ }^{1}$ Department of Social and Environmental Medicine, Osaka University Graduate School of Medicine, 2-2 \\ Yamadaoka, Suita, Osaka 564-0000, Japan \\ ${ }^{2}$ Graduate Division of Social Welfare, Kansai University of Welfare Sciences Graduate School, Japan \\ ${ }^{3}$ Occupational Health Training Center, University of Occupational and Environmental Health, Japan \\ ${ }^{4}$ Department of Mental Health, University of Tokyo Graduate School of Medicine, Japan
}

Received December 24, 2009 and accepted February 23, 2010

\begin{abstract}
We examined the prospective association of psychosocial job characteristics with employee job performance among 777 full-time employees at a manufacturing company in Japan, using data from a one-year follow-up survey. Psychosocial job characteristics were measured by the Job Content Questionnaire in 2008; job performance was evaluated using the item from the World Mental Health Survey Instrument in 2008 and 2009. The association between psychosocial job characteristics and job performance was tested using multiple regression analysis, controlling for demographic variables, work status, average working hours per day, job type and job performance in 2008. Job control and coworker support in 2008 were positively related to job performance in 2009. Stratified analyses revealed that job control for staff and coworker support for managers were positively related to job performance in 2009. These associations were prominent among men; however, supervisor support in 2008 was negatively related to job performance in 2009 among men. Job demand was not significantly related to job performance. Our findings suggest that it is worthwhile to enhance employees' job control and provide a mutually supportive environment to ensure positive employee job performance.
\end{abstract}

Key words: Job performance, Job stress, Demand-control model, Social support, Follow-up survey

\section{Introduction}

Job stress is one of the biggest health-related problems in the workplace ${ }^{1,2)}$. Various job stressors have harmful effects on employees' health, resulting in economic loss to the organization and society. In many previous studies on job stress, however, influences on health have been examined in terms of adverse health effects such as depression and cardiovascular disease ${ }^{3-5}$ ). When considering measures to reduce stress, it is necessary to take into account the productivity of the organization. For instance, addressing only job demands (i.e., workload reduction) is not feasible for workplace stress reduction because such a measure might decrease organizational productivity. Thus, in addition to health

*To whom correspondence should be addressed.

E-mail: eap-ins@forest.ocn.ne.jp issues, beneficial outcomes (e.g., employee performance) need to be examined in job stress research.

Employee health and satisfaction can coexist with organizational achievement. The concept of a "Healthy Work Organization" assumes an interaction between employee health and organizational achievement, with strength mutually advocated ${ }^{6}$. However, the relationship between psychosocial job characteristics including job stress and job performance has been addressed by only a few cross-sectional studies. Previous studies have shown that job control is related to employee motivation, work engagement, and commitment regardless of job demands $\left.{ }^{7}, 8\right)$. A supportive environment is potentially helpful to employee productivity because of the buffering effect against stress ${ }^{9)}$. In particular, supervisor support is considered beneficial for employee stress reduction as an external resource that improves engagement and productivity ${ }^{10)}$. However, there is no 
published prospective study on the relation between psychosocial job characteristics and job performance. The aim of this study was to examine the prospective relation of psychosocial job characteristics and job performance using the data of a one-year follow-up survey. Our hypothesis was that high job control and a supportive environment would be positively associated with high job performance one year later.

\section{Subjects and Methods}

\section{Sample and procedure}

Since 1999, an annual survey in the form of a selfadministered questionnaire has been carried out as part of occupational health management by the health and safety section of an electric device manufacturing company in Japan. We supported the execution and analysis of the survey as a staff of the Employee Assistance Program organization that has contracted with this company. The analysis in this study was based on the July 2008 and July 2009 surveys conducted in the company. Responses were obtained from 957 out of 987 full-time employees (response rate 97.2\%) in 2008; responses from 945 out of 985 full-time employees were obtained (response rate 96.1\%) in 2009. Data of 777 employees (637 men and 140 women; mean age $=40.6 \mathrm{yr}, \mathrm{SD}=10.8$ ) who completed both the questionnaires were subjected to the analysis.

The analysis was carried out with employees' informed consent, and full confidentiality of the information gathered during the entire procedure was guaranteed. Permission for this study was obtained from the Kansai University of Welfare Sciences Committee on Ethics.

\section{Variables}

Employees filled out a questionnaire on job performance, psychosocial job characteristics, demographic variables, work status, average working hours per day, and job type.

\section{(1) Job performance}

To assess job performance, a self-report job performance checklist was given to individual employees from the World Mental Health Survey Instrument ${ }^{11)}$. The instrument includes selected components of job performance (quantitative efficiency, job outcomes, special work success or failure) and global job performance. The series of questions about components of job performance are included to review critical aspects of job performance before assessing global job performance. For this study, only the single index of global job performance was derived. Respondents were asked to rate their overall job performance during the past four weeks on a "0-to-10" self-anchoring scale in which "0" was defined as the worst possible job performance a person could have on this job, and "10" was defined as best job performance on this job.

\section{(2) Psychosocial job characteristics}

To evaluate psychosocial job characteristics in 2008, a Japanese version of the Job Content Questionnaire (JCQ) was used ${ }^{12)}$. It is based on the job demand-control or demand-control-support model ${ }^{13)}$. The JCQ consists of three subscales: job demands (5 items), job control (9 items), and social support (4 items on supervisor support and 4 items on coworker support). Each item is rated on a four-point Likert-type scale (1=strongly disagree, 4=strongly agree). High scores indicate high job demands, high job control, and high social support. The sum of the weighted item scores was used as a scale score ${ }^{14)}$.

\section{(3) Potential confounding variables}

Information on basic demographic factors (gender, age, years of education, marital status) and occupational factors (work status, job type, average working hours per day) were collected. Age was classified into 5 groups (29 or younger, 30-39, 40-49, 50-59, 60+). Years of education were classified into two groups: less than $12(n=337,43.4 \%)$ or 13 and over $(n=440$, $56.6 \%)$. Marital status was classified into married $(n=473$, $60.9 \%)$, single $(n=257,33.1 \%)$, and divorced or widowed $(n=47,6.0 \%)$. Job type was classified into two groups: white-collar employees (administrator, clerk, salesperson, engineer, $n=424,54.6 \%)$ and blue-collar employees (assembler, $\mathrm{n}=353,45.4 \%$ ). Work status was classified into manager $(n=93,12.0 \%)$ and staff $(n=684$, $88.0 \%$ ). Average working hours per day were classified into under $9 \mathrm{~h}(\mathrm{n}=499,64.2 \%)$ and $10 \mathrm{~h}$ and over $(\mathrm{n}=278$, $35.8 \%)$.

\section{Statistical analysis}

The differences of the scores in job performance and psychosocial job characteristics according to demographic and occupational factors were examined by $t$-test or analysis of variance. These tests adjusted for multiple comparisons, where significant differences were acknowledged among more than two factors, using the Bonferroni technique. Means, standard deviations, and Cronbach's alpha coefficients for the job performance scale and JCQ subscales were calculated. Pearson's correlation coefficients were calculated between scales of job performance and psychosocial job characteristics. To assess the independent contributions of psychosocial job characteristics on job performance, we used a series 
of three multiple regression analyses, after controlling for gender, age, marital status, years of education, average working hours per day, job type, work status, and job performance in 2008. First, all the participants were included in the analysis. Then, two separate analyses were conducted for managers and other staff members and for men and women because effects of psychosocial job characteristics on job performance may differ among these demographics. Although analysis using further categorization in which work status and gender were combined might have provided beneficial information, we were not able to do this because of the small numbers in the cells. Instead, we adjusted for the respective variables for each stratified analysis. The statistical level of significance was set at the 5\% level. The analyses were performed using SPSS 17.0J for Windows (SPSS, Chicago).

\section{Results}

During the follow-up, there were no significant changes among variables except for working hours. Of all the employees, the number of those who reported shorter working hours ( $9 \mathrm{~h}$ or less per day) had increased in $2009(p<0.001)$. The number of managers who reported longer working hours increased in 2009, albeit statistically not significantly. Generally, the job performance score decreased slightly in 2009.

The demographic characteristics of participants and their associations with psychosocial job characteristics/performance scores are shown in Table 1. Job performance in 2008 was different among age groups. Multiple comparisons revealed that the older the age group, the higher the job performance score. Multiple comparisons also revealed that married employees showed higher job performance than single and divorced or widowed employees. Those who reported shorter working hours ( $9 \mathrm{~h}$ or less per day) reported higher job performance than those who reported longer working hours (10 h or more per day). As shown in relation to job performance in 2008, multiple comparisons revealed that the older the age group, the higher the job performance score in 2009. In addition, married employees showed higher job performance in 2009 than single and divorced or widowed employees. However, managers showed higher job performance in 2009 than staff members. The relation between working hours and job performance in 2009 was insignificant.

The levels of psychosocial job characteristics were also different according to demographic characteristics. Job demands were higher among men, those in their $30 \mathrm{~s}$ and $40 \mathrm{~s}$, and those who reported longer working hours than among their respective counterparts. Job control was higher among men, those over age 60 and those in their 40s, managers, those married, the highly educated, those who reported longer working hours, and white-collar employees than the respective demographic groups. Supervisor support was higher among managers and white-collar employees than among staff members and blue-collar employees, respectively. Coworker support was higher among men, those over $60 \mathrm{yr}$ of age and those $29 \mathrm{yr}$ or younger, managers, and white-collar employees than among respective demographic groups. All the differences among age groups and marital status were tested by multiple comparisons.

Table 2 shows means, standard deviations, ranges, Cronbach's alpha coefficients of psychosocial job characteristics and job performance variables, and Pearson's correlation coefficients among the variables. Cronbach's alpha coefficients were moderate for scales of job demand; they were sufficient for scales of job control, supervisor support, and coworker support. Job demands were positively associated with job control, but negatively associated with supervisor support. Job control was positively associated with all the other variables. The correlation levels between job control and job performance appeared slightly larger in 2009 than in 2008. There was a significantly positive correlation between supervisor support and coworker support. Coworker support was negatively associated with job performance in 2008. Performance in 2008 was positively correlated with performance in 2009.

Table 3 shows the independent relationship of each psychosocial job characteristic to job performance. In the analyses of all the employees, results indicate that job control and coworker support in 2008 were positively associated with job performance in 2009 ( $p=0.010$, $p=0.038$, respectively), after controlling for gender, age, marital status, years of education, average working hours per day, work status, job type, and job performance in 2008.

Examined separately (managers and staffs, men and women) the relationship of psychosocial job characteristics and job performance is shown in Table 3. In managers, coworker support was positively associated with job performance $(p=0.001)$. Among staff members, job control was positively associated with job performance $(p=0.019)$. In men, job control and coworker support were positively associated with job performance $(p=0.001$, $p=0.016$, respectively). However, in men, supervisor support in 2008 was negatively associated with job performance in $2009(p=0.005)$. No significant associations among psychosocial job characteristics and job performance were seen in women. 


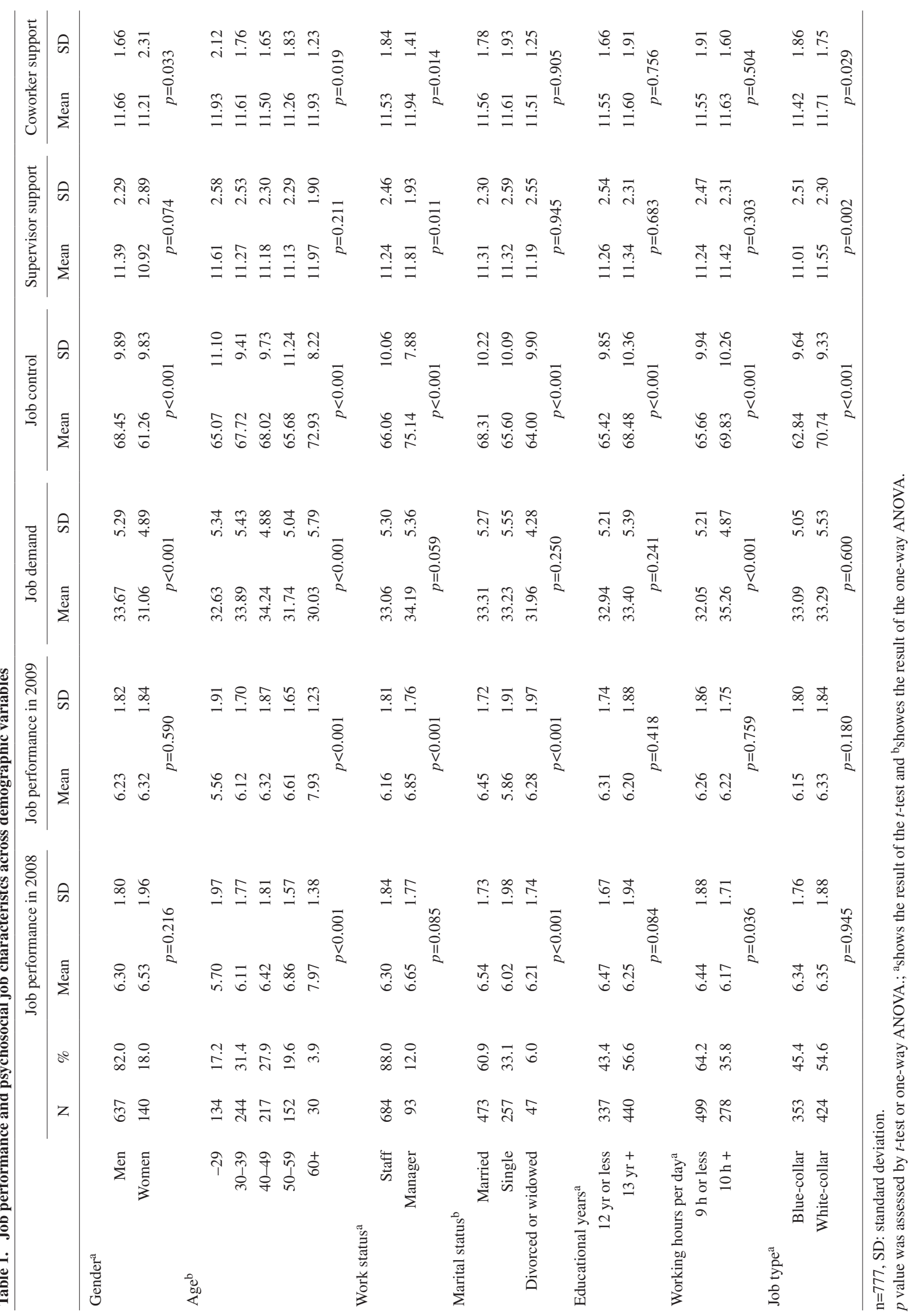


Table 2. Mean, SD, reliability value and correlation coefficients of job stress scales, job performance scale

\begin{tabular}{|c|c|c|c|c|c|c|c|c|c|c|c|c|c|c|}
\hline & \multirow[b]{3}{*}{ Mean } & \multirow[b]{3}{*}{ SD } & \multirow[b]{3}{*}{ Range } & \multirow[b]{3}{*}{ Cronbach' $\alpha$} & \multicolumn{10}{|c|}{ Correlation coefficients } \\
\hline & & & & & & & Supervisor & & Coworker & & Performance & & Performance & \\
\hline & & & & & Control & $p$-value & Support & $p$-value & Support & $p$-value & in 2008 & $p$-value & in 2009 & $p$-value \\
\hline Job Demand & 33.20 & 5.32 & $12-48$ & 0.69 & 0.203 & 0.000 & -0.119 & 0.001 & 0.006 & 0.868 & -0.007 & 0.838 & -0.018 & 0.614 \\
\hline Job Control & 67.15 & 10.25 & $26-96$ & 0.78 & & & 0.268 & 0.000 & 0.256 & 0.000 & 0.099 & 0.006 & 0.148 & 0.000 \\
\hline Supervisor Support & 11.31 & 2.41 & $4-16$ & 0.91 & & & & & 0.473 & 0.000 & -0.070 & 0.052 & -0.044 & 0.222 \\
\hline Coworker Support & 11.58 & 1.80 & $4-16$ & 0.82 & & & & & & & -0.100 & 0.005 & 0.002 & 0.951 \\
\hline Performance in 2008 & 6.34 & 1.83 & $1-10$ & - & & & & & & & & & 0.545 & 0.000 \\
\hline Performance in 2009 & 6.25 & 1.82 & $1-10$ & - & & & & & & & & & & \\
\hline
\end{tabular}

$\mathrm{n}=777$.

Table 3. Multiple regression analysis of psychosocial job characteristics on following year job performance

\begin{tabular}{|c|c|c|c|c|c|c|c|c|c|c|}
\hline & & & \multicolumn{4}{|c|}{ Work Status } & \multicolumn{4}{|c|}{ Gender } \\
\hline & \multicolumn{2}{|c|}{ Total $(\mathrm{n}=777)^{\mathrm{a}}$} & \multicolumn{2}{|c|}{ Manager $(n=93)^{b}$} & \multicolumn{2}{|c|}{ Staff $(n=684)^{b}$} & \multicolumn{2}{|c|}{$\operatorname{Men}(n=637)^{\mathrm{c}}$} & \multicolumn{2}{|c|}{$\operatorname{Women}(n=140)^{\mathrm{c}}$} \\
\hline & $\beta$ & $p$-value & $\beta$ & $p$-value & $\beta$ & $p$-value & $\beta$ & $p$-value & $\beta$ & $p$-value \\
\hline Job Demand & -0.035 & 0.282 & 0.027 & 0.784 & -0.038 & 0.289 & -0.065 & 0.061 & 0.112 & 0.157 \\
\hline Job Control & 0.093 & 0.010 & 0.020 & 0.848 & 0.088 & 0.019 & 0.127 & 0.001 & -0.066 & 0.447 \\
\hline Supervisor Support & -0.068 & 0.052 & -0.161 & 0.114 & -0.051 & 0.181 & -0.104 & 0.005 & 0.057 & 0.548 \\
\hline \multirow[t]{2}{*}{ Coworker Support } & 0.072 & 0.038 & 0.329 & 0.001 & 0.043 & 0.249 & 0.089 & 0.016 & 0.025 & 0.788 \\
\hline & \multicolumn{2}{|c|}{ adjusted $\mathrm{R}^{2}=0.31$} & \multicolumn{2}{|c|}{ adjusted $\mathrm{R}^{2}=0.35$} & \multicolumn{2}{|c|}{ adjusted $\mathrm{R}^{2}=0.30$} & \multicolumn{2}{|c|}{ adjusted $\mathrm{R}^{2}=0.36$} & \multicolumn{2}{|c|}{ adjusted $\mathrm{R}^{2}=0.20$} \\
\hline
\end{tabular}

a: adjusted for gender, age, marital status, work status, performance in 2008, education, average working hours per day, job type; b: adjusted for gender, age, marital status, performance in 2008, education, average working hours per day, job type; c: adjusted for age, marital status, work status, performance in 2008 , education, average working hours per day, job type; $\beta$ : standardized regression coefficient.

\section{Discussion}

The relationship between psychosocial job characteristics and job performance was examined in a one-year follow-up study. Even after controlling for demographic factors, average working hours per day, work status, job type, and job performance in 2008, we found that employees with high job control and high coworker support reported higher job performance after one year. Stratified analyses revealed that psychosocial job characteristics related to job performance were different according to work status and gender. Coworker support appeared relevant for managers; job control was reportedly relevant for staff members. Associations between psychosocial job characteristics and job performance were prominent among men. However, a significant negative association was found between supervisor support and job performance among men. Job demands did not have a significant influence on job performance.

It is understandable that ensuring employees make full use of their skill and decision authority, and thereby enhancing their job control, would improve their productivity $\left.{ }^{7}, 8\right)$. Previous studies have shown that job control is related to employees' motivation, work engagement, and commitment, and is associated with increased job performance ${ }^{8,10)}$. Thus, high job control would influence job performance through employees' attitudes toward work. However, the potential relationship between job control and job performance revealed in the study cannot be fully interpreted causally because the research design was cross-sectional. In addition, the occupational category was limited. It also should be noted that the prospective association between job control and job performance was prominent among staff members. A possible reason for the non-significant, albeit positive, relationship of job control and job performance among managers might be that there was already a high level of job control and job performance in that group (Table 1); hence, a significant difference was not obtained. The low statistical power (small sample number) could also explain the results.

Coworker support showed a prospective effect on job performance. This finding supports the hypothesis that a supportive environment can have a beneficial effect on consequent job performance. The correlation analysis in 2008 showed a negative association between coworker support and job performance (Table 2), although the statistical significance disappeared after controlling for demographic variables, work status, average working hours per day, job type, and job performance in 2008 (data not shown). However, these correlations were all crosssectional. Hence, direction of causality is not implied 
(i.e., employees with low job performance received support at the time of the survey, and vice versa). Thus, a prospective observation such as ours would be of value.

Our stratified analysis revealed a strong association between coworker support and job performance in 2009 among managers. We offer two explanations for this finding. First, compared with ordinal staff, coworker support may be a more important resource for managers to solve their problems effectively because managers must carry out tasks which are difficult to share with others. In such an 'isolated' situation, coworker support, either emotional or tangible, would be of great help. In a large sample of 11 Japanese companies, Usami and Kosugi ${ }^{15)}$ examined the effects of perceived social support on employees' coping strategies according to occupational positions. They found that managers, with sufficient discretion, expected support from their coworkers to complete their explicit role to a larger extent than did the ordinal staff. In contrast, ordinal staff members had a greater expectation than managers for support from their managers to do their jobs. Second, socio-economic circumstances at the time of the survey might have influenced these results. The business performance and production of the company studied deteriorated as a consequence of an economic depression (the "Lehman Shock"), which was reflected in decreased productivity among blue-collar workers. On the other hand, managers might have had to work longer and needed coworker support to compensate for the productivity loss.

Associations between psychosocial job characteristics and job performance were prominent among men. Although there are some exceptions, the health effect of job stressors derived from the job demand-controlsupport model has been reported to be stronger in men than in women ${ }^{16)}$. Possible explanations may include differences between genders in relation to sensitivity to various life stressors ${ }^{17}$ ) and lack of comprehensive measurements in relation to multiple burdens other than work for women ${ }^{16)}$. The demographic characteristics of women might explain why there were no significant associations in women, at least in part. The majority of women in this study constituted ordinal, blue-collar staff. The nature of their routine work might not have necessarily required higher control and support either from supervisors or coworkers. The small number of women, resulting in low statistical power, was also attributable to the null results.

The negative relation between supervisor support and job performance among men in our study contradicts previous findings $\left.{ }^{7}, 10\right)$. Evidence regarding the effect of social support is somewhat inconsistent, even suggesting that social support might have negative effects ${ }^{18)}$.
A possible explanation for this finding is a mismatch in need for support and offer of support ${ }^{19}$ ). Only when employees cannot deal sufficiently with a problem, they obtain support. That is, when necessary support is offered, it reduces the stress reaction. On the other hand, support not corresponding to current needs or circumstances does not have a stress reduction effect. Compared with coworker support, which is often mutually requested, supervisor support is sometimes offered irrespective of the subordinate request. Furthermore, supervisor support does not have much impact on the able subordinates who are high performers. In addition, too much support from a supervisor can ruin the subordinate's autonomy, resulting in a decrease in self-evaluated job performance. It has been reported that receiving imposed support elicits negative reactions except when there is an unsolvable problem, but even then the effect of imposed support is neutral and not positive ${ }^{20)}$.

Differences in samples studied and outcomes between previous cross-sectional studies and our study might account for the discrepancies in findings regarding supervisor support and job performance. In one study, immediate supervisor support was related to job satisfaction and productivity in 211 traffic enforcement agents $(92 \text { men, } 119 \text { women })^{10)}$. In that study, the indices of productivity were based on number of summonses, a type of negative index. In another study, the effect of social support on job stressors (role ambiguity, role overload, role conflict, and future job uncertainty) was examined across a broad range of occupations ${ }^{9}$. Results have shown a beneficial effect only in the groups with lower occupational level. Researchers surmised that those in lower occupations expected supervisor support because they had low control in their jobs. Further studies are necessary to examine the association of supervisor support and job performance.

These findings were obtained from one company, and the external validity is limited. To generalize the findings, it is necessary to investigate in different types of companies and settings. In the future, an intervention study would be of value. Regarding outcome measurements, only self-report indices were employed, which raises the issue of possible response bias ${ }^{21}$. In particular, further standardization and validation of the job performance measurement are necessary in a Japanese setting, given that a single index of global job performance was employed. However, the measured outcome was job performance during the last four weeks, and the independent variable (psychosocial job characteristics) was derived from one year ago. Thus, reversed causality was unlikely. Furthermore, we controlled for job performance level from the previous year. Still, more objective outcomes are necessary to strengthen the value 
of the findings.

Despite these limitations, our findings suggest that it is worthwhile to enhance employees' job control and provide a mutually supportive environment to ensure positive employee job performance.

\section{Acknowledgements}

We express our sincere appreciation to all the participating employees.

\section{References}

1) Karasek R, Theorell T (1990) Healthy work: stress, productivity, and the reconstruction of working life. Basic Books, New York.

2) Karasek R (1992) Stress prevention through work reorganization: a summary of 19 international case studies. ILO Conditions of Work Digest: Preventing Stress at Work 11, 23-41.

3) Van der Doef M, Maes S (1998) The job demand-control (-support) model and physical health outcomes: a review of the strain and buffer hypotheses. Psychol Health 13, 909-36.

4) Van der Doef M, Maes S (1999) The job demand-control (-support) model and psychological well-being: a review of 20 years of empirical research. Work Stress 13, 87-114.

5) Kristensen TS (1996) Job stress and cardiovascular disease: a theoretical critical review. J Occup Health Psychol 1, 246-60.

6) National Institute for Occupational Safety and Health (1998) Stress at work. DHHS (NIOSH) Publication No. 99-101. NIOSH, Cincinnati.

7) Demerouti E, Bakker AB, de Jonge J, Janssen P, Schaufeli WB (2001) Burnout and engagement at work as a function of demands and control. Scand J Work Environ Health 27, 279-86.

8) Salanova M, Agut S, Peiró JM (2005) Linking organizational resources and work engagement to employee performance and customer loyalty: the mediation of service climate. J Appl Psychol 90, 1217-27.

9) Marcelissen FH, Winnubst JA, Buunk B, de Wolff CJ (1988) Social support and occupational stress: a causal analysis. Soc Sci Med 26, 365-73.

10) Baruch-Feldman C, Brondolo E, Ben-Dayan D, Schwartz J (2002) Sources of social support and burn- out, job satisfaction, and productivity. J Occup Health Psychol 7, 84-93.

11) Kessler RC, Barber C, Beck A, Berglund P, Cleary PD, McKenas D, Pronk N, Simon G, Stang P, Ustun TB, Wang P (2003) The World Health Organization Health and Work Performance Questionnaire (HPQ). J Occup Environ Med 45, 156-74.

12) Kawakami N, Kobayashi F, Araki S, Haratani T, Furui $\mathrm{H}$ (1995) Assessment of job stress dimensions based on the job demands-control model of employees of telecommunication and electric power companies in Japan: reliability and validity of the Japanese version of the Job Content Questionnaire. Int J Behav Med 2, 358-75.

13) Karasek R, Baker D, Marxer F, Ahlbom A, Theorell T (1981) Job decision latitude, job demands, and cardiovascular disease: a prospective study of Swedish men. Am J Public Health 71, 694-705.

14) Karasek R, Brisson C, Kawakami N, Houtman I, Bongers P, Amick B (1998) The Job Content Questionnaire (JCQ): an instrument for internationally comparative assessments of psychosocial job characteristics. J Occup Health Psychol 3, 322-55.

15) Usami H, Kosugi $S$ (2008) The effects of perceived social support on coping strategies by those in managerial positions. Job Stress Res 15, 277-85 (in Japanese).

16) Belkić K, Landsbergis PA, Schnall, PL, Baker D (2004) Is job strain a major source of cardiovascular disease risk? Scand J Work Environ Health 30, 85-128.

17) Virtanen M, Koskinen S, Kivimäki M, Honkonen T, Vahtera J, Ahola K, Lönnqvist J (2008) Contribution of non-work and work-related risk factors to the association between income and mental disorders in a working population: the Health 2000 Study. Occup Environ Med 65, 171-8.

18) Ganster DC, Victor B (1988) The impact of social support on mental and physical health. Br J Med Psychol 61, 17-36.

19) Cohen S, Wills TA (1985) Stress, social support, and the buffering hypothesis. Psychol Bull 98, 310-57.

20) Deelstra JT, Peeters MCW, Schaufeli WB, Stroebe W, Zijlstra FRH, van Doornen LP (2003) Receiving instrumental support at work: when help is not welcome. J Appl Psychol 88, 324-31.

21) Crowne DP, Marlowe D (1960) A new scale of social desirability independent of psychopathology. J Consult Psychol 24, 349-54. 